\title{
Discurso, opinión y episteme. Los inmigrantes y la COVID-19 por la prensa chilena
}

\author{
Discourse, opinion and episteme. \\ Immigrants and COVID-19 in the chilean press
}

\author{
Elizabeth Torrico-Ávila \\ Universidad de Atacama, Chile \\ elizabeth.torrico@uda.cl \\ https://orcid.org/0000-0002-9309-4055 \\ Jaime González-González \\ Universidad de Talca, Chile \\ jagonzag1974@gmail.com \\ http://orcid.org/0000-0003-2293-2434
}

\begin{abstract}
Resumen
En las sociedades democráticas actuales, los medios de prensa, conocidos como "el cuarto poder" y que generalmente están a cargo de las elites locales, han adquirido un rol fundamental en la naturalización de discursos en la comunidad ejerciendo la fuerza de incluso influenciar a la opinión pública en temas políticos, sociales, religiosos y económicos, entre otros. Siendo el problema de estudio la influencia que la emisión de cierto tipo de discurso tiene sobre el receptor de este, el objetivo de este artículo es reflexionar acerca del vínculo existente entre el discurso, la opinión pública y epistemología de la prensa escrita en torno a la migración en tiempos de COVID-19 en Chile. Los resultados de la observación de once diarios por medio del Análisis Crítico del Discurso arrojan que, por un lado, los actores tales como autoridades son nominalizados, mientras que los extranjeros son asimilados a un grupo o invisibilizados completamente. Por otro lado, los temas que emergen del análisis son la pobreza, la vulnerabilidad y la discriminación. Este estudio apunta a problematizar los discursos que provienen de los medios escritos desde una perspectiva crítica y a contribuir a una construcción dialógica del otro de forma objetiva alejada de visiones preconcebidas y estigmatizadoras difundidas por los medios de comunicación.
\end{abstract}

\section{Palabras clave}

Discurso, episteme, medios de prensa, migración, COVID-19, discriminación.

Forma sugerida de citar: Torrico-Ávila, E., \& González-González, J. (2021). Discurso, opinión y episteme. Los inmigrantes y la COVID-19 en la prensa chilena. chilena. Universitas, 34, pp.195-213. 


\begin{abstract}
In the current democratic societies, the media, known as "the fourth power" and that are generally in charge of the local elites, have achieved a crucial role in the naturalization of discourses in the community having the capacity to even influence the public opinion in political, social, religious and economic areas, among others. Being the problem of study the influence that the expression of a certain type of discourse has over its receivers, the goal of this article is to reflect about the link between the discourse, the public opinion and the press epistemology regarding the immigration in Chile during COVID-19 times. The results from the examination of eleven newspapers employing a Critical Discourse Analysis approach inform us that, on the one side, the actors such as authorities are nominalized, whereas the foreigners are assimilated in a group or invisibilized altogether. On the other hand, the themes that emerge from the data analysis are poverty, vulnerability and discrimination. This study aims at problematizing the discourses that come from the press from a critical perspective in order to contribute to the dialogical construction of the other from an objective point of view away from preconceived and stigmatized views spread by the media.
\end{abstract}

\title{
Keywords
}

Discourse, episteme, press media, migration, COVID-19, discrimination.

\section{Introducción}

El estudio de los discursos públicos ha ocupado a numerosos autores. Debido a las características del objeto, el interés por este ha sido manifiesto en las ciencias sociales y la literatura vinculada al terreno de la lingüística y la sociología. Desde esta perspectiva, su interés pasa tanto por su papel en las representaciones sociales, como su incidencia en el plano del poder. Considerando este último punto, la emisión de discursos en ámbitos públicos engloba una serie de problemáticas vinculadas a cultura, identidad y política nacional e internacional.

En relación con el objeto, Jakobson (1986) lo define inicialmente como expresión lingüística. No obstante, el autor complejiza el concepto al sostener que el discurso es ante todo una realidad colectiva, debido a que siempre el discurso individual se genera con un intercambio. Desde esta perspectiva, no puede existir un emisor sin un receptor, argumento válido 
incluso para el "discurso interior" - no emitido - ya que el diálogo se halla en la base incluso del discurso interior.

Con semejanzas y diferencias, Chomsky (1981) define el objeto como un "espejo de la mente", un producto de la inteligencia humana, creado en cada individuo mediante operaciones que están fuera del alcance de la voluntad o la conciencia. Desde esta perspectiva, el autor establece un vínculo entre conciencia individual y expresión lingüística, de tal manera que el estudio del lenguaje puede ser instrumentado para alcanzar cierta comprensión respecto de las características específicas de la inteligencia humana.

Por el contrario, para Bourdieu (1990), el discurso no puede ser definido solo como la expresión lingüística de un individuo, ni en la competencia lingüística individual, sino como una expresión que está dentro de un contexto. Para Bourdieu, un emisor no genera un discurso en el aire, sino que emite un mensaje cuyo destinatario es un conjunto de emisores y receptores que recepcionan y valorizan el discurso del primer hablante.

Una perspectiva alternativa se observa en Giddens (2003). Para el teórico, el discurso constituye un tipo de práctica, donde se instrumentan una serie fórmulas sociales para generar comunicación intersubjetiva. En este tereno y desde el concepto de "conciencia discursiva", Giddens aborda la expresión lingüística como un tipo de acto motivado por la conciencia humana. Esta conciencia es resultado tanto del agente humano inteligente, como de las estructuras simbólicas que interiorizan los sujetos en calidad de actores participantes de una sociedad.

A pesar del valor heurístico que aportan estas perspectivas teóricas, se observa un vacío conceptual al reflexionar sobre el vínculo del discurso, con problemáticas ligadas a la opinión medial, distintos tipos de nacionalismo y poblaciones inmigrantes en tiempos de pandemia. En este terreno, se extraña un trabajo que se haga cargo de establecer los nexos conceptuales entre la idea de discurso, con nomenclaturas como opinión pública y visión de mundo en tiempos de pandemia. Es desde esta laguna que parte este trabajo. Nuestro interés pasa por reflexionar sobre el maridaje teórico entre discurso, opinión pública y epistemología en la prensa escrita chilena, considerando la publicación de contenidos en torno a la migración extranjera al país en tiempos de COVID-19. Sobre esta base, nuestra pregunta directriz es: ¿cuáles son los principales tópicos discursivos, opinativos y epistémicos presentes en estos medios en torno a la población inmigrante en Chile? Se sostiene como hipótesis que estos tópicos son discriminantes, nacionalistas 
y civilizatorios. En este sentido, la opinión de los medios refleja una forma de conocer, fundada en la valoración cultural de Occidente, discriminando a cualquier colectividad que porte representaciones y prácticas distantes a este esquema simbólico.

El trabajo se valdrá de una serie de casos ilustrativos de prensa escrita, donde se tratarán las opiniones mediales hacia las poblaciones migrantes en el actual contexto de pandemia. Los casos son abordados con el fin de aportar elementos a la reflexión teórica sobre el nexo entre discurso medial y epistemología en torno a un otro diferente. Sobre esta base, los contenidos del artículo consideran un primer apartado, donde se aborda el maridaje teórico entre discurso y medios de comunicación. El texto continúa con una sección que da tratamiento teórico a las nociones de opinión pública y episteme. El artículo finaliza con el análisis inicial de una serie de opiniones de la prensa escrita en torno a los inmigrantes en Chile.

\section{Discurso y medios de comunicación}

Luego de la introducción que nos informa del vínculo entre la lingüística, discurso y los medios de comunicación, nos dirigimos hacia el Análisis Crítico del Discurso, que es el enfoque más apropiado para el presente artículo. Esta es una disciplina amplia y compleja como fue explicado por Wodak y Meyer (2001) compuesta por diferentes teorías metodologías y herramientas de recolección de datos que la definen como "una perspectiva de academia crítica, una teoría y método de analizar la manera en que los individuos e instituciones usan el lenguaje" (Richardson, 2007, pp. 1-2). Siendo el objeto de estudio para esta disciplina el vínculo del uso del lenguaje con el poder social (Mohammedwesam, 2017, p. 1).

Richardson (2007) tiene una clara visión de esta disciplina en relación con el análisis de los medios de comunicación escritos. El autor argumenta que:

El análisis crítico del discurso ofrece interpretaciones [y explicaciones] de los significados de los textos (...); situar lo que está escrito o dicho en el contexto en el que ocurre, en vez que solo resumir patrones o regularidades en los textos; y argumentar que el significado textual es construido a través de una interacción entre el productor, el texto y el consumidor en vez que simplemente sea leído desde la página por los lectores en exactamente la misma manera. (p. 15) 
El discurso en los medios refleja intereses y posturas ideológicas de la élite gobernante (Fowler, 1991; Fairclough, 1989, 2001, 2003; Van Dijk, 1997, 1998a, 1998b). En esta línea, Androutsopoulos (2010, p. 183), sostiene que "las ideologías lingüísticas no son neutrales u objetivas, sino que sirven a los intereses de individuos o grupos específicos, es decir, ellos están siempre formulando desde una perspectiva social particular y tienen referentes y objetivos particulares". Entonces, la forma en que los actores que participan en eventos narrados por los medios son representados depende de las ideologías asociadas al medio escrito correspondiente (Chiluwa, 2011, p. 197) argumentando que las representaciones de los actores o agrupación a la que ellos pertenecen en los medios están asociados a ideologías específicas. El hecho de que los diarios se asocian a ciertas ideologías, se espera que por medio de las noticias se legitimicen opiniones contenidas por estos medios. Es así cómo estos discursos difundidos por la prensa naturalizan discursos que finalmente tienen influencia en la formación de la opinión pública de la comunidad que los consume con el objetivo político de distraer la atención de la población de un determinado problema social (Reisigl \& Wodak, 2001, p. 145). Es por ello que en esta sección desvelaremos cómo los medios seleccionados emplean estrategias discursivas para construir realidad y representar a los inmigrantes como uno de los actores sociales impactados por la crisis sanitaria en Chile durante el periodo de pandemia y expondremos la responsabilidad que tienen medios en la formación de la opinión pública acerca de estos inmigrantes.

Desde el comienzo de la pandemia en Chile, la prensa ha informado de las dificultades que han enfrentado los extranjeros en el país y los riesgos a los que se han expuesto los inmigrantes ilegales que han ingresado a Chile por pasos no habilitados. Ello ha sido entretejido por medio del empleo de discursos emitidos por autoridades nacionales que al emplear estrategias discursivas persuasivas, han dibujado una realidad que moldea la opinión pública acerca del extranjero en Chile en tiempos de la COVID-19. Para revelar los mensajes discriminatorios implícitos en el texto, nos enfocaremos en los actores que participan en ellos y las acciones con las que se asocian y, así, evidenciar la construcción discursiva de hostilidad hacia el inmigrante en Chile durante la pandemia.

La prensa nacional está llena de noticias relacionadas con la llegada de inmigrantes a Chile. Los comentarios emitidos en esos espacios están divididos a favor y en contra del inmigrante. Sin embargo, persiste una visión negativa acerca de ellos. Entre esos comentarios, también aparecen las posturas de 
diferentes autoridades políticas, académicas, religiosas y culturales, frente al suceso. Esos actores, por un lado, representan la visión que proviene del grupo al cual pertenecen. Por otro lado, los discursos de estos actores son enfatizados por medio de la nominalización, invisibilización o asimilación de los actores a través del empleo de estrategias discursivas (van Leeuwen, 1996, 2007) con el objetivo de contribuir a la línea editorial del medio de prensa en cuestión. En consecuencia, los lectores de estas noticias, se ven influenciados por la construcción discursiva de los inmigrantes emitida por los medios locales que son los que emiten el discurso en cuestión. Esto predispone a la comunidad, "el mercado lingüístico", frente al extranjero naturalizando conductas a favor o en contra del extranjero, es decir, el "lingüístico" que se manifiesta por medio de la expresión lingüística que es el discurso.

De acuerdo con lo anterior, no se debe menospreciar el poder que ejercen los medios en moldear la opinión pública. Siendo estos una herramienta que puede naturalizar los objetivos de la élite. La herramienta que la élite busca controlar por medio del manejo de los medios es el discurso, ese que es consumido por la sociedad y que de acuerdo con Johnstone (2002, p. 9) "da forma al mundo y el discurso es formado por el mundo". Tan crucial es esa selección del discurso que Foucault (1981, pp. 52-53) indica que "el discurso no es simplemente aquello que traduce luchas o sistemas de dominación, sino que es la cosa por la cual hay lucha, el discurso es el poder que debe ser aprovechado". Es por ello que el lenguaje que seleccionan los medios para referirse a las condiciones de los inmigrantes en Chile es crucial para la construcción de la realidad y la influencia que esa construcción tiene en la sociedad.

Bourdieu y Wacquant (2001) dan un ejemplo del poder del discurso. Según ellos existe un nuevo tipo de discurso al que llaman "Neolengua Liberal" haciendo eco a Orwell (1949). Ese nuevo léxico es utilizado para naturalizar realidad en la sociedad, por ejemplo, COVID-19 y su normalización discursiva a nivel mundial. Chomsky (DiEM25, 2020) informa de cómo se ha asociado el discurso de guerra con el discurso de la COVID-19. Por ejemplo, el exministro de Salud chileno, Jaime Mañalich (2020), quien hablaba de "la guerra contra la COVID-19", "los doctores luchan a diario con el corona", entre otros discursos relacionados a la pandemia. Este tipo de léxico fue decolonizado desde su contexto original, la guerra, y recolonizado en uno nuevo, la salud (Fairclough, 1996, 2002; Massey, 2013). El frecuente uso del discurso de Mañalich asociado a la presencia de los inmigrantes y difundido por los medios puede influenciar a la opinión pública receptora de esas noticias y afecta al extranjero. 
La influencia que ejerce la prensa escrita en la comunidad receptora de esos discursos se contrapone con la postura de prensa libre que es la labor de los medios de comunicación (Ejupi et al., 2014). Es así сото Груевски (2004) y Gruevski (2004) advierten que en la actualidad la toma de decisiones hecha por los habitantes y congresistas depende fuertemente de la información obtenida. La prensa tenía un rol fiscalizador informando al lector de la realidad convirtiéndose así en el cuarto poder. Sin embargo, de acuerdo con Ramón (Силјановска, 2007, p. 96), exeditor del Le Monde Diplomatique "los medios han sido por un largo periodo de tiempo una fuente de ciudadanía, conocida como el cuarto poder, un poder que se ha opuesto a las decisiones del gobierno las cuales pudieran haber tenido un efecto dañino en la gente. El cuarto poder ya no tiene más su poder", especialmente cuando los medios se emplean para influenciar a la opinión pública en temas sociales y políticos como la inmigración. En consecuencia, el rol que poseen los medios para fortalecer la opinión pública y la creación de pensamiento libre está influenciado por la gran cantidad de noticias que circulan en las redes sociales que están tomando el rol que antes pertenecía a la prensa. Como resultado, se está persuadiendo al lector quien está tomando decisiones desinformadas y que pueden ser cruciales para la comunidad. Por ejemplo, la intervención rusa en las elecciones presidenciales de los Estados Unidos de América del 2016 (Mayer, 2018).

\section{Opinión y episteme tras los discursos mediales}

El concepto de "opinión pública" ha sido estudiado por numerosas aproximaciones teóricas. En este terreno, Habermas (2009) aborda la idea desde el origen histórico de esta, situando la nomenclatura en el siglo XIX europeo con el desarrollo de la prensa escrita. Para él, la noción es entendida como "publicidad burguesa". En este sentido, la opinión pública constituye el acto de publicar el común raciocinio de una colectividad que se distinguen de otros por haber accedido a la propiedad y a la instrucción. Por sus características simbólicas, constituye un "ámbito social", diferente del tejido económico y de las relaciones de poder formal.

La propuesta de Vasilachis (2013) va más lejos: para esta autora, la prensa participa directamente en la forma de construir a los sujetos. En este sentido, los medios se conforman de una serie de categorías que terminan articulando las representaciones sociales de los individuos. Este aspecto resulta 
relevante, ya que permite entender la opinión de la prensa desde el terreno de las representaciones humanas, considerando distintos niveles de abstracción.

Las representaciones humanas presentan un importante componente intelectual. En este último terreno, la prensa orienta su acción desde fundamentos del conocer vinculados a la educación universitaria, la cultura profesional del periodismo y las comunicaciones. El acto de comunicar está ligado a una serie de procedimientos intelectuales aprendidos en la universidad, espacio epistémico que Löwy (1979) definió como "universo de valores cualitativo". Para el autor, este entorno simbólico se distingue de otros por presentar valores cualitativos para interpretar a la sociedad.

No obstante, los entornos simbólicos de carácter académico presentan semejanzas y diferencias con otros contextos culturales. En este terreno, Foucault (1972) aporta elementos al análisis con su concepto de "episteme", idea que apunta a identificar distintas formas de conocer en las colectividades humanas, de tal manera que la actividad académica puede ser entendida como una forma de conocimiento como cualquier otra. Esta episteme tiene consecuencias en los actos humanos, tal como se puede apreciar en el terreno de los discursos orales o escritos.

Por un rumbo semejante encontramos la obra de Gellner (1998). Centrando el análisis en la intelectualidad y sus comportamientos, sostiene que la epistemología y el contexto político constituyen verdaderas variables independientes de las prácticas intelectuales. En este terreno, Gellner sostiene que el punto de partida del trabajo intelectual pasa por la epistemología. No obstante, esta también tiene consecuencias en el comportamiento político de los profesionales de la inteligencia, ya que los sujetos generan prácticas según el modo en que piensan y la contingencia que enfrentan. De esta manera, una postura epistemológica tiene consecuencias en la acción cotidiana y en la política, hecho que se puede observar en el comportamiento actuado y en el hablado. La práctica escritural no sería la excepción.

En torno a este artículo, el contexto que sirve para la reflexión es la migración latinoamericana al país en presencia de la COVID-19. El objeto de este trabajo está centrado en los discursos mediales de la prensa escrita chilena en torno a los inmigrantes en momentos en que el mundo atraviesa una contingencia de salud ligada al COVID-19. Para que esta reflexión gane en heurística, seleccionamos once periódicos digitales nacionales en torno a la problemática. Se trata de los diarios: La Cuarta, La Nación, El Mercurio, La Tercera, SoyChile, TeleSur, El Siglo, Pauta, Crónica Digital, Pauta y AA, 
prensa que, por sus características, se presentan como articuladores de representaciones sociales a escala nacional y como constructores simbólicos de sujetos, tal como lo propone Vasilachis (2013). De esta materia tratarán las siguientes líneas.

\section{Análisis de la prensa desde los rasgos discursivos y epistémicos de la opinión medial}

Según Instituto Nacional de Estadísticas (2020) la población migrante en Chile bordea 1500000 personas mayoritariamente latinoamericanas. De ellos, solo el $20 \%$ tiene un trabajo calificado mientras que el 10,8\% es clasificado como pobre. Esta población queda en riesgo durante la pandemia siendo los medios chilenos los que informan acerca de la crisis sanitaria actual que atraviesa el país. Estos medios están teñidos por ideologías de las élites que están detrás de ellos traspasando a la comunidad por medio del discurso esas ideologías para posteriormente naturalizar posturas frente a un determinado tema social. Por ejemplo, la inmigración en Chile.

Los medios escritos que forman parte de este estudio son examinados desde el comienzo de la pandemia en Chile en marzo 2020 hasta la primera semana de octubre 2020. De esa observación emanan temas como el desempleo, la salud, la pobreza, la estigmatización y la falta de redes de apoyo. Mientras que las palabras con connotación negativa que se han empleado para referirse a la inmigración en Chile son: delito, riesgo, ilegal, "coyote", clandestino, denunciado, caótico, expulsar, tráfico, criminal, denunciar y desmantelar.

Sin embargo, no todo el discurso asociado al tema de estudio es negativo. En defensa de los extranjeros, han aparecido actores desde el universo político, académico y religioso. Por ejemplo, la expresidenta, Michelle Bachelet manifiesta su preocupación por la crisis migratoria, argumentando que los inmigrantes están muy afectados por la COVID-19 y que es nuestra responsabilidad ayudarlos (La Cuarta, 2 mayo). Otro actor que emite discursos en favor de los inmigrantes proviene de la academia. José Manuel Cárdenas, académico de la Facultad de Psicología de la Universidad de Talca, a la luz de los resultados entregados por una encuesta realizada por CENEMUTALCA informa que un $47 \%$ de los inmigrantes temen contraer la COVID-19 (Crónica Digital, 20 de agosto 2020). 
El sacerdote jesuita Felipe Berrios, proveniente del ámbito religioso quien vive en "La Chimba" Antofagastina compuesta por inmigrantes, denuncia la vulnerabilidad a la que están expuestos los extranjeros que se manifiesta en la falta de redes de apoyo. Los medios destacan que los inmigrantes están sin sus familias, desempleados y sin dinero (EMOL, 2020, 19 agosto). Las personas con estas características son las que Berrios define como "los nuevos pobres" (El Mercurio de Calama, 4 septiembre 2020a). La vulnerabilidad en la que se encuentran, los obliga a pedir dinero en las calles ya que no tienen recursos ni para poder regresar a sus países (El Mercurio de Calama, 4 septiembre 2020b). Mientras tanto, "los nuevos pobres", viven en hacinamiento, en la calle y en pobreza donde las posibilidades de contagiarse son mayores (Pauta.cl, 5 junio 2020; Agencia EFE, 8 mayo).

Por otro lado, Javiera Cerda, del Servicio Jesuita a Migrantes de Arica, reconoce el mayor aumento de la inmigración ilegal en Chile por pasos no habilitados de toda la última década donde el $50 \%$ se produjo entre 2018 y 2019 . Cerda (La Tercera, 2 octubre) informa que ha aumentado exponencialmente el inmigrante venezolano posterior al funcionamiento de la Visa de Responsabilidad Democrática. El incremento fue de nueve venezolanos el 2017 por paso no habilitado a 3000 el 2019 y esto va en incremento (EMOL, 2020, 9 octubre).

$\mathrm{Al}$ contrario, los actores sociales quienes han cuestionado la inmigración en Chile provienen mayoritariamente del mundo político. El exministro del interior, Andrés Chadwick, quien, frente al ingreso de inmigrantes ilegales al país, argumenta que debemos proteger los límites nacionales (La Cuarta, 22 Julio 2020). Algo similar expresó el presidente de la república, Sebastián Piñera, diciendo que: las fronteras aéreas, marítimas y terrestres deben ser reforzadas para evitar el ingreso de la pandemia al país (El Siglo, abril 2020). Frente al mismo tema, el ministro del interior Pérez (La Nación, 2020, 29 de septiembre; Schuller, 2020) indicó que 506 de 762 son inmigrantes ilegales en residencias sanitarias.

Mientras que, desde el Departamento de Policía Internacional de Iquique, al mes de septiembre, la policía de investigaciones ha informado el ingreso por paso no habilitado de 1493 inmigrantes, de ellos 615 son venezolanos (La Nación, 2020). El ministro agregó que los inmigrantes son aceptados por los chilenos mientras que esto sea de forma regulada y ordenada siguiendo los requerimientos para integrarse a Chile. La irregularidad en el ingreso al país ha causado dificultades en regiones y comunas, para los chilenos y para los in- 
migrantes mismos e indicó que en estos momentos tenemos cerradas las fronteras, pero cuando se regularice la situación el problema puede ser mayor. Es por ello que se hace pertinente que el Estado introduzca una Ley Migratoria para combatir esta irregularidad (La Nación, 2020, 28 septiembre).

El Canciller Allamand (La Nación, 2020a, 2020b), agrega que se espera durante la semana tener una ley que regularice la acción en las fronteras y del ingreso de los inmigrantes ilegales y, así, evitar desacuerdos con la oposición y desmotivar la creciente inmigración ilegal y añade que el ingreso ilegal de los inmigrantes es un crimen y se implementaran los regalamientos para expulsar a esos inmigrantes de Chile. Finalmente, el intendente de Tarapacá, Miguel Quezada (2020), explicó que los funcionarios públicos enfrentan una difícil situación en las residencias sanitarias de Iquique que albergan mayoritariamente venezolanos que ingresaron ilegalmente desde los pasos no habilitados entre Chile-Bolivia y concluye argumentando que el gobierno no está a favor de la inmigración ilegal en el que son los mismos extranjeros quienes se auto-denuncian para acceder a las residencias sanitarias. Esto puede poner en riesgo a los ciudadanos de la región y a los mismos inmigrantes (La Nación, 2020). Finalmente, otro actor proviene desde la seremi de Salud, Rossana Díaz, quien indica que en Iquique hasta hace una semana había alrededor de 600 extranjeros en las residencias sanitarias habilitadas. Ellos previamente se auto denunciaron tras llegar a Chile según el protocolo, ingresando al país por un paso no habilitado. Finalmente, la edil informa que en Antofagasta hay 378 inmigrantes en similares recintos (Soy Chile 7 octubre 2020).

Las noticias relacionadas con los inmigrantes en Chile en tiempos de pandemia se dividen en dos. El primer grupo contiene las noticias de migrantes que ya están en Chile. El segundo grupo se compone de los inmigrantes que han llegado al país durante la pandemia. Desde el primer grupo, los diarios informan de la falta de empleo que ellos enfrentan. Esos trabajos en algunos casos eran informales y precarios, sin embargo, les permitían sobrevivir (La Tercera 26 marzo 2020). En términos de salud, debido a los trabajos que realizaban, ellos no tienen derecho a beneficios de salud dejándolos aún más vulnerables (El Mercurio de Calama 4 septiembre-a). De acuerdo con TeleSur (2020), la realidad de los extranjeros en Chile es difícil ya que están expuestos al COVID-19 sobre todo porque estando en la irregularidad no pueden acceder al sistema de salud nacional. En relación con la estigmatización, La Tercera (8 mayo 2020) informa que algunos creen que 
quienes traen la COVID-19 a Chile son los inmigrantes y que es labor del país asegurar el bienestar de los chilenos en primer lugar de una crisis económica. Estos discursos son racistas y, de acuerdo con van Dijk (1993, p. 21), es "una forma de dominación" y el omitir a quién los emite es una estrategia discursiva llamada supresión (van Leeuwen, 1996, p. 38). Por otro lado, algunos inmigrantes desolados por la actual crisis, buscan la repatriación desde sus embajadas, AA (2020) informa que cientos de bolivianos, peruanos, colombianos y venezolanos están esperando regresar a sus países de origen escapando de la vulnerabilidad causada por la COVID-19. En esta situación, ellos acusan discriminación, racismo y maltrato físico (El Mercurio de Calama, 4 septiembre-b; La Cuarta 22 abril 2020; El Siglo, abril 2020).

En torno al último grupo de inmigrantes los diarios locales han informado empleando los siguientes titulares que informan acerca del gran ingreso de inmigrantes entre enero y agosto siendo en su mayoría venezolanos (La Nación, 2020) y continúa la noticia argumentando que estos inmigrantes son los más numerosos que han ingresado a lo largo del año (La Nación, 2020). Este tipo de notas predispone negativamente a la comunidad frente a los venezolanos avecindados en el país.

Otro titular informa al lector acerca del ingreso ilegal de inmigrantes y de su tráfico por medio de la analogía (van Leeuwen, 2007, p. 99) de forma alarmista enfatizando el aumento de $53 \%$ a $91 \%$, pero a la vez destaca que ellos tienen educación secundaria y terciaria rendida (La Tercera 2 octubre 2020) y agrega que la Fiscalía informó acerca de un incremento en este tipo de infracciones y el OS-9 de Carabineros examinó el funcionamiento de los "coyotes" y extranjeros que cruzaban la frontera de manera ilegal siendo la mayor parte de ellos venezolanos (La Tercera 2 octubre 2020). Para dar objetividad a la nota, se emplea la estrategia de autoridad que proviene en este caso de la policía informando que el OS-9 ha detenido transportistas definidos como "coyotes" entre 2019 y 2020 siendo esta una nueva forma de organización criminal que opera en Tacna-Perú y la componen venezolanos quienes ganan dinero desde sus propios coterráneos. Según carabineros el costo del servicio son diversos, pero bordea US\$ 100 y US $\$ 300$ para asegurar el paso exitoso hacia Chile (Rivera \& Ojeda, 2020).

Por el contrario, Soy Chile (7 octubre 2020) emplea discursos a favor de los inmigrantes venezolanos enfatizando su peregrinación por cinco países de América del Sur para llegar a Chile e informa que el venezolano, Rafael Pérez, esposa e hijos caminaron durante tres días por la costa para llegar a 
Antofagasta (Soy Chile 7 octubre 2020). Rafael Pérez (Soy Chile 7 octubre 2020) relata que, al llegar a Chile, el grupo de alrededor de 25 extranjeros, se autodenunció frente a la policía y posteriormente fueron trasladados a residencias sanitarias a cumplir la cuarentena Permanecer en la residencia sanitaria les permitió descansar del viaje.

Un examen inicial de estos discursos a favor y en contra de la inmigración en el país, permite observar que se clasifica a los extranjeros como "ellos" y al nacional como "nosotros". Según van Dijk (1992, p. 245) es una estrategia discursiva empleada para clasificar y dividir a los que pertenecen a un grupo de los que no, siendo estos últimos segregados por la comunidad.

Otra estrategia discursiva empleada por los medios de comunicación es la construcción de los actores y de roles que se emplean en los discursos emitidos por autoridades de gobierno o de conocimiento (van Leeuwen, 1996, 2007). Esa estrategia se llama nominalización y autoridad del experto respectivamente (van Leeuwen, 1996; van Leeuwen, 2007). El objetivo de esta estrategia es destacar a las personas que emiten los comentarios alineados a los objetivos propios de la élite, es decir, quien goza de estatus, privilegios, ingresos y acceso a buenos empleos (van Dijk, 1993), que controla esos medios de comunicación. Por el contrario, los migrantes estigmatizados no son nombrados, sino que están clasificados en un grupo como la nacionalidad. Esa estrategia discursiva se conoce como asimilación (van Leeuwen, 1996). Así, las personas asimiladas pierden identidad y pasan a constituir un todo que es demonizado de acuerdo con lo que relatan los medios de comunicación. En los medios examinados, podemos observar que varias autoridades locales fueron nominalizadas, mientras que solo un inmigrante fue nombrado por los ellos.

El análisis centrado en la opinión pública de estos medios, se observa cómo la prensa escrita articula representaciones en torno al migrante desde el terreno de los líderes de opinión, sea político, académico o religioso. Junto a ello, los periódicos construyen simbólicamente a las poblaciones inmigrantes en calidad de colectividades desde sus prácticas textuales. Estos actos escriturales tributan al "paradigma sarmientino", una visión de mundo ligada a la dicotomía entre civilización y barbarie, tal como sostienen Santa Cruz (1988), Jiménez y González (2019) en el análisis de la prensa chilena. De esta manera, existe un modelo cultural detrás de los textos periodísticos que informan de este esquema simbólico operando en los actos comunicativos de estos diarios. Esta episteme clasifica a las colectividades migrantes 
en calidad de humanidad disminuida, producto tanto de su precariedad material, como de su potencial patológico producto de la contingencia mundial de salud que proviene "desde fuera" del país. De esta manera, se observa un enfoque civilizatorio donde el "nosotros" (Chile), se posiciona ventajosamente frente al "otro" proveniente del exterior.

Para concluir, el objetivo de esta sección apuntaba a examinar la construcción discursiva de los inmigrantes en Chile en tiempos de pandemia hecha por los medios de prensa. Después de un breve análisis hemos observado que ellos son puestos en posición de desventaja y de pobreza siendo estigmatizados e visibilizados como un todo perteneciente a un grupo por medio de la estrategia discursiva de asimilación. Mientras que la clase al poder es nominalizada, por un lado, emiten discursos estigmatizadores en contra de los inmigrantes, mientras que, por otro lado, el actor nominalizado es categorizado como una autoridad experta quien invita a respetar los derechos del otro. Finalmente, la característica frecuente de los discursos es la división hecha entre "nosotros", los chilenos, y "ellos", los otros, los inmigrantes ilegales y clandestinos con los cuales se asocian discursos negativos y quienes pueden traer la pandemia al país, según informa La Tercera (8 de mayo 2020).

\section{Reflexiones finales}

Este trabajo reflexionó sobre el nexo entre discurso, opinión pública y episteme de los discursos emitidos por la prensa chilena en torno a la inmigración al país en tiempos de pandemia. La problemática del ensayo se centró en los tópicos discursivos, opináticos y epistémicos presentes en estos medios, proponiendo que estos presentaban dimensiones discriminantes y nacionalistas. La opinión de la prensa era entendida como una práctica textual, tributaria de una epistemología y una contingencia política, acto comunicativo caracterizado por la valoración cultural a Occidente y discriminatoria de otros estilos de vida.

Considerando la discusión teórica presente en el artículo, más el análisis inicial de los discursos mediales presentados en la última sección del texto, formulamos algunas reflexiones finales. La primera tiene que ver con los discursos mismos y sus principales características en torno al "otro". En este terreno, se observa una distinción entre un "nosotros" de un "ellos", fenómeno explicado por van Dijk (1992, p. 245) como una estrategia discursiva empleada para clasificar y dividir a los que pertenecen a un grupo de los que no, siendo estos últimos segregados por la comunidad. 
Una segunda reflexión pasa por la estrategia discursiva empleada por los medios de comunicación nacionales para la construcción de actores y roles. En este plano, resulta evidente la dicotomía observada en los procedimientos empleados, "nominalizando" a las autoridades nacionales, frente a la etiquetación colectiva de las poblaciones extranjeras asentadas en Chile desde la clasificación de "inmigrantes". Estas estrategias tributarían a una visión de mundo vinculada al "paradigma sarmientino", modelo que establece una antinomia entre Occidente en calidad de civilización, frente a la barbarie representada por las culturas no occidentales. Desde esta episteme, la prensa escrita instrumenta una serie de prácticas textuales que articulan las representaciones de líderes de opinión provenientes de la política, la academia y el mundo católico. Junto a ello, podemos observar cómo estos actos comunicativos habilitan la construcción simbólica de los sujetos desde la emisión misma de la opinión publicitada, hecho que se aprecia en el caso de los migrantes mismos.

El principal alcance de este trabajo está ligado a la investigación empírica. Un estudio de los discursos mediales sobre la inmigración en Chile debe pasar por el análisis de las distintas dimensiones de opinión pública presentes en las secciones de la prensa escrita. Una mención semejante se puede hacer en el terreno de los modelos culturales detrás de las prácticas textuales. En este sentido, la indagación en torno a titulares, páginas editoriales, noticias y artículos de opinión deben ser abordadas con el rigor metodológico que prescribe el análisis de discurso. Serán futuros trabajos los que deberán hacerse cargo de esta tarea.

\section{Bibliografía}

Allamand,A. (2020a, 29 septiembre). Gobierno registra 5147 inmigrantes ilegales entre enero y agosto, la mayoría venezolanos. La Nación. https://bit.ly/3a5j4bw

Allamand, A (2020b, 15 octubre). Gobierno llama a parlamentarios a aprobar ley de migración para enfrentar ingresos clandestinos. La Nacion.cl. https://bit. ly/3d3r7ay

Androutsopoulos, J. (2010). Ideologizing ethnoloctal German. In S.A. Johnson \& M.M. Tommaso (Eds.), Language ideologies and media discourse. Texts, practices, politics, vol. 10, (pp. 182-202). Continuum.

Bourdieu, P. (1990). Sociología y cultura. Editorial Grijalbo.

Bourdieu, P., \& Wacquant, L. (2001). NewLiberalSpeak: Notes on the new planetary vulgate. Radical Philosophy (105), 2-5. https://bit.ly/3aRBqMi 
Chiluwa, I. (2011). Media Representation of Nigeria's Joint Military Task Force in the Niger Delta Crisis. Int J Humanit Soc Sci, 1(9), 197-208. https://bit. ly/3a8CdJK

Chomsky, N. (1981). Reflexiones acerca del lenguaje. Adquisición de las estructuras cognoscitivas. Editorial Trillas.

DiEM25 [DiEM25]. (2020). Noam Chomsky: Coronavirus, ¿qué está en juego? [Archivo de video]. https://bit.ly/3jIlQXn

Ejupi, V., Siljanovska, L., \& Iseni, A. (2014). The Mass Media And Persuasion. European Scientific Journal, 10(14). https://bit.ly/3qaSK5c

Fairclough, N. (1989). Language and power. Longman.

Fairclough, N. (1996). Technologization of discourse. En C. R. Caldas-Coulthard \& M. Coulthard (Eds), Texts and Practices. Routledge.

Fairclough, N. (2001). Language and power (2nd ed.). Longman.

Fairclough, N. (2002). Language in new capitalism. Discourse and Society, 13(2), 163-166. https://doi.org/10.1177/0957926502013002404

Fairclough, N. (2003). Analysing discourse: Textual analysis for social research. Routledge.

Foucault, M. (1972). La arqueología del saber. Siglo XXI Ediciones.

Foucault, M. (1981). The Order of discourse. En R. Young, Untying the text: A poststructural reader (pp. 51-77). https://bit.ly/3a8vb7v

Fowler, R. (1991) Language in the news: Discourse and ideology in the press. Routledge.

Gellner, E. (1998). Language and Solitude. Wittgenstein, Malinowski and the Habsburg Dilema. Cambridge University Press

Giddens, A. (2003). La constitución de la Sociedad: bases para la teoría de la estructuración. Amorrortu.

Gruevski, T. (2004). Communications and Culture. Studentski zbor.

Habermas, J. (2009). Historia y crítica de la opinión pública. Editorial Gustavo Gil.

Jakobson, R. (1986). Ensayos de Lingüística General. Editorial Artemisa.

Jiménez, M., \& González, J. (2019). ¿Etnia o nación? Los aymaras desde la opinión de la prensa de Chile y Bolivia. Revista Encrucijada Americana, 11(1), 5-23. https://bit.ly/3rHpXWw

Johnstone, B. (2002). Discourse analysis. Blackwell.

Löwy, M. (1979). Para uma sociologia dos intelectuais revolucionários. A evolucao política de Lucács (1909-1929). Lech Livraria Editora Ciencias Humanas.

Mañalich, J. (2020, 03 de abril). Balance de Coronavirus. https://bit.ly/3rKnZEv

Mayer, J. (24 septiembre 2018). How Russia Helped Swing the Election for Trump. The New Yorker. https://bit.ly/3jDdyQj 
Mohammedwesam, A. (2017). Critical discourse analysis of war reporting in the international press: the case of the Gaza war of 2008-2009. Palgrave Communications, 3(1), 1-11. https://doi.org/10.1057/s41599-017-0015-2

Orwell, G. (1949). 1984. Penguin Random House.

Pérez, V. (2020, 29 de septiembre). Gobierno registra 5147 inmigrantes ilegales entre enero y agosto, la mayoría venezolanos. La Nación. https://bit.ly/3paZpet

Pérez, V. (2020, 28 de septiembre). Gobierno llama a parlamentarios a aprobar ley de migración para enfrentar ingresos clandestinos. La Nacion.cl. https:// bit.ly/3d3r7ay

Reisigl, M., \& Wodak, R. (2001). Discourse and Discrimination: Rethorics of racism and antisemitism. Routledge.

Richardson, J.E. (2007). Analysing newspapers: An approach from critical discourse analysis. Palgrave Macmillan.

Rivera, V., \& Ojeda, J. (2020, 02 de octubre). Tráfico de migrantes sube 53\% y 91\% de extranjeros ingresados ilegalmente tiene educación media y superior completa. La Tercera. https://bit.ly/3rHjOcC

Santa Cruz, E. (1988). Análisis histórico del periodismo chileno. Nuestra América.

Schuller, P. (2020, 29 de septiembre). Gobierno registra 5147 inmigrantes ilegales entre enero y agosto, la mayoría venezolanos. La Nación. https://bit.ly/3rNJ695

Van Dijk, T. (1992). Racism and argumentation: Race riot rhetoric in tabloid editorials. En F.H. van Eemeren (Ed.), Argumentation illuminated. Dordrecht.

Van Dijk, T. (1993). Elite discourse and racism. Sage Publicactions.

Van Dijk, T. (Ed.) (1997). Discourse as social interaction, vol 2. Sage.

Van Dijk, T. (1998a). Opinions and ideologies in the press. In A. Bell \& P. Garrett (Eds.), Approaches to media discourse, vol.2, (pp. 21-63). Blackwell.

Van Dijk, T. (1998b). Critical discourse analysis. In D. Schiffrin, H. Hamilton \& D. Tannen (Eds.), Handbook of discourse analysis (in preparation). https:// bit.ly/3jEsDBu

Van Leeuwen. T (1996). The representation of social actors. In C. Caldas-Coulthard \& M. Coulthard (Eds.), Texts and Practices: Readings in Critical Discourse Analysis (pp. 32-70). Routledge.

Van Leeuwen, T. (2007) Legitimation in discourse and communication. Discourse and Communication, 1(1), 91-112. https://doi.org/10.1177/1750481307071986

Vasilachis, I. (2013). Pobres, pobreza, identidad y representaciones sociales. Gedisa. Wodak, R., \& Meyer, M. (2001). Methods of critical discourse analysis. Sage.

Груевски, Т. (2004). Комуникации и култура. Студентскизбор. 
Силјановска, Л. (2007). Влијанието на масовните медиуми во формирањето на европските вредности Тетово. ArberiaDesign.

\section{Diarios}

AA (2020). El drama de los inmigrantes sudamericanos varados en Chile a causa del coronavirus. $A A$. https://bit.ly/3a89Jjb

Agencia EFE (08 de mayo 2020). El “sueño" chileno de los migrantes se desvanece con el coronavirus. Agencia EFE. https://bit.ly/3jEtwKk

Crónica Digital (20 de agosto 2020). La mitad de los migrantes quedaron sin trabajo en Chile por COVID-19. Crónica Digital. https://bit.ly/3tJbWt3

El Mercurio de Calama (04 de septiembre 2020a). Organizaciones abordan la compleja situación de migrantes en la pandemia. El Mercurio de Calama.

(04 de septiembre 2020b). Pareja venezolana sobrevive pidiendo dinero en las esquinas de Calama. El Mercurio de Calama.

El Siglo (abril 2020). COVID-19: La dramática situación de migrantes. El Siglo. https://bit.ly/3ryvy $1 \mathrm{c}$

La Cuarta (22 de abril 2020). ¡Eso es discriminación, racistas!: inmigrantes haitianos se niegan a cumplir cuarentena. La Cuarta. https://bit.ly/3rERyax

La Cuarta (02 de mayo 2020). Michelle Bachelet pide apoyo a migrantes afectados por COVID-19. La Cuarta. https://bit.ly/3qd0tzN

La Cuarta (22 de julio 2020). El peligroso "negocio" de los coyotes de la frontera. La Cuarta. https://bit.ly/3rGdP8a

La Nación (29 de septiembre 2020). Gobierno registra 5147 inmigrantes ilegales entre enero y agosto, la mayoría venezolanos. La Nación.cl. https://bit. ly/2NaEjQ6

La Nación (15 de octubre 2020). Gobierno llama a parlamentarios a aprobar ley de migración para enfrentar ingresos clandestinos. La Nacion.cl. https://bit. ly/2MLnk7i

La Tercera (26 de marzo 2020). Vulnerabilidad y pobreza: cómo afecta a los migrantes y sus familias la pandemia de coronavirus. La Tercera. https:// bit.ly/3a6zTTi

La Tercera (08 de mayo 2020). Migraciones y COVID. Una relación peligrosa para el proyecto de Ley. La Tercera. https://bit.ly/3a8fnBJ

La Tercera (02 octubre 2020). Tráfico de migrantes sube $53 \%$ y $91 \%$ de extranjeros ingresados ilegalmente tiene educación media y superior completa. $\mathrm{La}$ Tercera. https://bit.ly/3tLElic 
Pauta (05 de junio 2020). Enfrentar la COVID-19 desde la migración. Pauta.cl. https://bit.ly/3rHosr6

Emol.com (19 de agosto 2020). Migrantes en Chile durante la pandemia: Un 30\% perdió el trabajo y un $60 \%$ dice que no regresaría a su país. Emol.com. https://bit.ly/3q801S4

Emol.com (09 de octubre 2020). Ingreso irregular de inmigrantes al país se duplicó en agosto: La mayoría son venezolanos. Emol.com. https://bit.ly/3p9w17h

Soychile.cl (07 de octubre 2020). Antofagasta: La caminata de las familias venezolanas que cruza cinco países sudamericanos. Soychile.cl. https://bit. ly/3cYNpub

Fecha de envío: 2020/I0/31; Fecha de aceptación: 2021/02/I2;

Fecha de publicación: 2021/03/01 